University of Nebraska - Lincoln

DigitalCommons@University of Nebraska - Lincoln

3-3-2004

\title{
A NEW SAMPLING PROTOCOL FOR THE ENDANGERED AMERICAN BURYING BEETLE, NICROPHORUS AMERICANUS OLIVIER (COLEOPTERA: SILPHIDAE)
}

Jon C. Bedick

University of Nebraska-Lincoln, jbedick@shawnee.edu

Brett C. Ratcliffe

University of Nebraska-Lincoln, bratcliffe1@unl.edu

Leon G. Higley

University of Nebraska-Lincoln, Ihigley1@unl.edu

Follow this and additional works at: https://digitalcommons.unl.edu/entomologypapers

Part of the Entomology Commons

Bedick, Jon C.; Ratcliffe, Brett C.; and Higley, Leon G., "A NEW SAMPLING PROTOCOL FOR THE ENDANGERED AMERICAN BURYING BEETLE, NICROPHORUS AMERICANUS OLIVIER (COLEOPTERA:

SILPHIDAE)" (2004). Papers in Entomology. 45.

https://digitalcommons.unl.edu/entomologypapers/45

This Article is brought to you for free and open access by the Museum, University of Nebraska State at DigitalCommons@University of Nebraska - Lincoln. It has been accepted for inclusion in Papers in Entomology by an authorized administrator of DigitalCommons@University of Nebraska - Lincoln. 


\title{
A New Sampling Protocol for the Endangered American Burying Beetle, Nicrophorus americanus Olivier (Coleoptera: Silphidae)
}

\author{
Jon C. Bedick, ${ }^{1}$ Brett C. Ratcliffe ${ }^{2}$ and Leon G. Higley ${ }^{3}$ \\ ${ }^{1,3}$ Department of Entomology, University of Nebraska \\ Lincoln, NE 68588-0816, U.S.A. \\ jcbedick@yahoo.com; lhigley1@unl.edu \\ ${ }^{2}$ Systematics Research Collections, W436 Nebraska Hall \\ University of Nebraska, Lincoln, NE 68588-0514, U.S.A. \\ bratcliffe1@unl.edu
}

\begin{abstract}
The endangered American burying beetle, Nicrophorus americanus Olivier, presently occurs in small and widely scattered areas on the periphery of its former range. As part of the recovery plan for this insect implemented by the U.S. Fish and Wildlife Service (USFWS), we conducted surveys in Nebraska to ascertain its presence. Additionally, we examined various trapping methods and procedures in the course of our survey work. We compared the effectiveness of different trap designs, trap placement, timing of trapping, types and amounts of bait, and monitoring traps. We also developed methods to reduce beetle mortality in traps. Our work offers more effective sampling procedures for $N$. americanus and suggests the current USFWS sampling protocol should be modified. New procedures include larger traps, moist soil substrate, a soil berm to the edge of the trap, longer trapping season, and increased distances between traps. A moist soil substrate, in combination with a shade-giving rain cover, precludes the necessity of servicing all traps by 9 AM each day (as mandated in the current protocol), a task that is logistically difficult or impossible if there are many traps. The sampling procedures we have identified as most appropriate for $N$. americanus will also improve sampling for other silphid species.
\end{abstract}

Throughout the 1990s, numerous surveys (many unpublished) were conducted in many states to locate remnant populations of the endangered American burying beetle, Nicrophorus americanus Olivier. This species was formerly distributed throughout 35 states and three Canadian provinces in eastern North America from Nova Scotia to western Nebraska and from the upper peninsula of Michigan to Texas (U.S. Fish and Wildlife Service 1991). In the last century it has disappeared from over $90 \%$ of its historic range (Lomolino et al. 1995). The beetle now occurs in only seven states: Block Island off the southern coast of Rhode Island (Kozol 1989, 1991), Penikese and Nantucket Islands in Massachusetts (Muths and Scott 2000), eastern Oklahoma and western Arkansas (U.S. Fish and Wildlife Service 1991; Creighton et al. 1993; Lomolino et al. 1995), central Nebraska (Ratcliffe 1996; Ratcliffe and Jameson 1992; Bedick et al. 1999), southern South Dakota (Backlund and Marrone 1997), and southeastern Kansas (Miller and McDonald 1997).

Because of the precipitous decline in the distribution of $N$. americanus, it was proposed as an endangered species (Recce 1988) and placed on the endangered species list in August 1989. Various ideas have been postulated to explain the decline of this species, but no clear answer has emerged; see Bedick et al. (1999) for a summary of various hypotheses and associated literature. The USFWS, in cooperation with the scientific community, formulated a recovery plan (U.S. Fish and Wildlife Service 1991) that is now being implemented. One goal of the recovery plan is to locate undocumented populations of $N$. americanus. As a part of this plan, the USFWS published 
a protocol for live-trapping $N$. americanus, which has been widely used. This protocol has also been mandated by state and other federal agencies for those working on the American burying beetle so as to provide a standard that reduces trap mortality. A standard procedure is crucial because surveys are conducted by people with varying degrees of knowledge and experience. The USFWS protocol was based on standards used to sample the Block Island population. Other than the Block Island work, there has been little done to identify the most effective sampling methodology for $N$. americanus. Further, issues associated with survey (presence-absence) are different from issues associated with population sampling where population abundance or density estimates are desired (Southwood 1978). This latter point is especially important in characterizing remaining populations of endangered species like $N$. americanus. Consequently, in conjunction with our work on $N$. americanus distribution and abundance in central Nebraska (Bedick et al. 1999), we conducted studies to identify better sampling procedures for the beetle. Specifically, we studied, beetle activity patterns, trap design and placement, and type and amount of carrion used as bait to improve trap efficiency. We report here what we believe to be an improved sampling procedures for $N$. americanus based on our research.

\section{Materials and Methods}

Study Area. We surveyed for the American burying beetle in central Nebraska in 1995 to establish the range of the Gothenburg, Nebraska population. The survey was conducted between 6 July and 26 August in five adjacent counties in south-central Nebraska, centering on the city of Gothenburg. The five adjacent counties were Dawson, Gosper, Phelps, Lincoln, and Frontier. We also surveyed in two counties in the far north-central part of the state. The two northern counties were surveyed to confirm a capture of an American burying beetle by an eleven year old girl who had a specimen of the endangered beetle in her 4-H collection at the Nebraska State Fair in 1994. The northern counties surveyed were Cherry and Keya Paha. In 1996, additional data were collected between 15 June and 31 August with an intensive survey for $N$. americanus in Lincoln County and limited surveys in Custer and Hayes counties.

The main study areas encompass an area known as the Loess Hills, which are the eroded remnants of an ancient plain. The soil is composed of a highly erodable loess/ sand mixture. Most of the larger canyons in this area run north/south, and the prevailing summer winds are from the south-southeast. The area has few trees, and most of these are concentrated in the canyons and draws, while the hilltops tend to remain treeless. Where trees are present, junipers (Juniperus virginiana L. and J. scopulorum Sarg.) are dominant. Other tree species present are box elder (Acer negundo L.), hackberry (Celtis species), and cottonwood (Populus sargenti or $P$. deltoides Marsh).

The study area is sparsely populated and used primarily as grazing land for beef cattle. Corn, alfalfa, sorghum, wheat, and prairie hay are grown in a few of the wider canyons, and reservoirs have been constructed at the mouths of several of the canyons. Grazing levels varied throughout the study area due to the differing management practices of landowners. This resulted in highly variable plant cover. Native prairie grass species, such as little blue stem (Schizachyrium scoparius Michaux), are found throughout the study area while some of the introduced weedy brome species, such as downy, hairy, and Japanese Bromus species, are found in areas of overgrazing. Numerous woody plants, including yucca (Yucca glauca Nutt.), skunk bush sumac (Rhus aromatic Ait.), winged sumac (Rhus copallina L.), chokecherry (Prunus virginiana L.), wild plum (Prunus americana Marsh), and honeysuckle (Lonicera species), were found in the study area. 


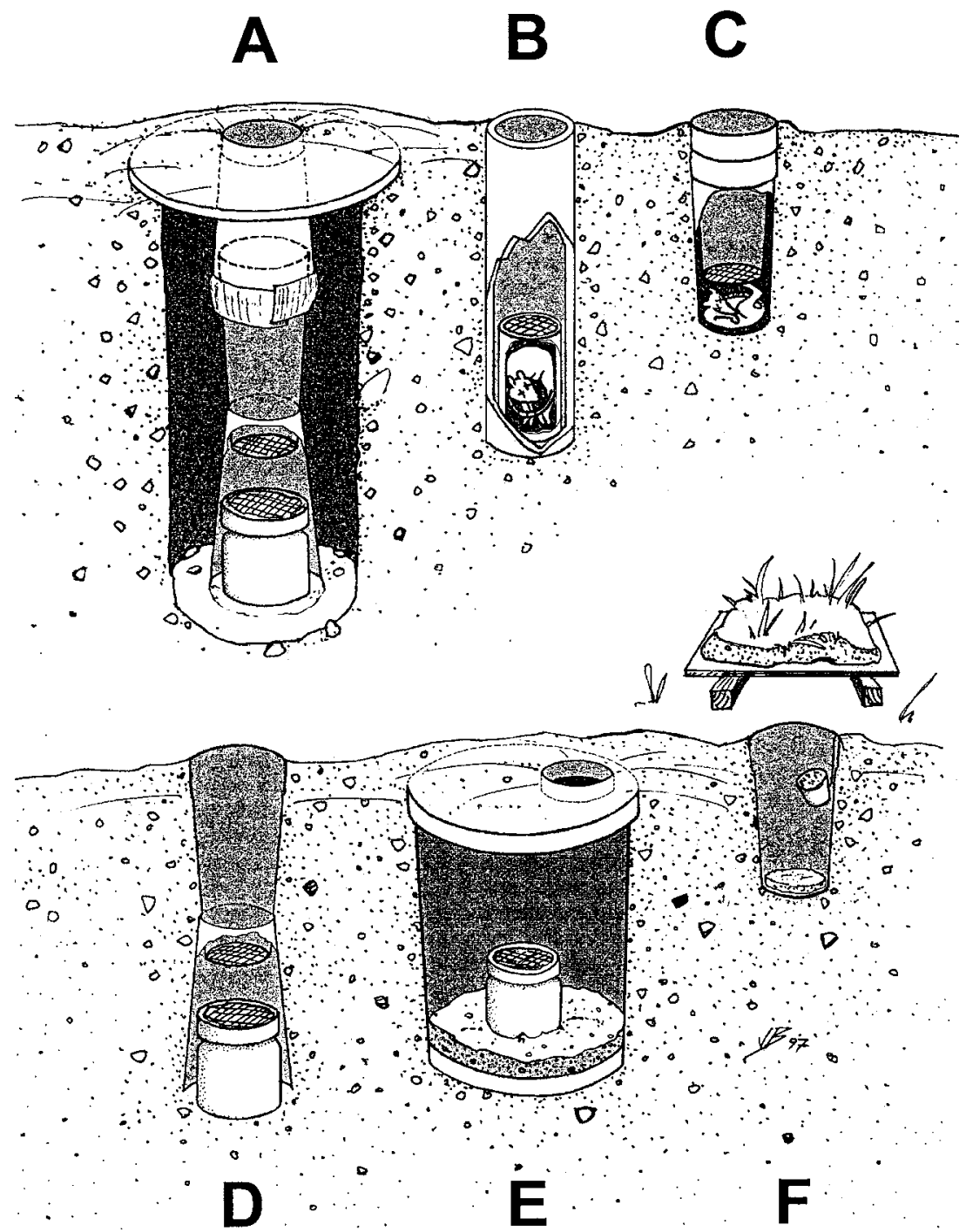

Fig. 1. Other trap designs tested during this study. a) Three cup trap designed to allow rapid servicing; b) pipe trap constructed from PVC pipe; c) double cup trap allows variably sized carrion to be used; d) variation of double cup trap; e) covered bucket trap restricts air movement resulting in bait aging slowly; f) single plastic cup trap (1.2 liter).

Trap Types. We evaluated various trap designs (Fig. 1) to test their suitability for sampling $N$. americanus. Traps tested including carrion piles, pipe traps, double bucket traps, single bucket traps, and five different cup traps.

The carrion pile method involved placement of whole animals (opossum, badger, coyote, house cat, and/or raccoon) in a suitable location. The carrion piles were left out to decay with most of the mass being reduced by insects in three to six days depending 
on weather and initial size of the animal used. The carrion piles were checked each morning for the presence of $N$. americanus, and they continued to be checked until advanced decay (or a severe fly infestation) rendered the remains unattractive to $N$. americanus. A thorough search for beetles was made on, under, and in the carrion.

The pipe-trap consisted of an open ended PVC pipe $45 \mathrm{~cm}$ in length with an internal diameter of $10.2 \mathrm{~cm}$ (Fig. 1b). A second PVC pipe with an outside diameter of $9.5 \mathrm{~cm}$ and a length of $15 \mathrm{~cm}$ was placed inside the first pipe, and both were then buried vertically. The second, smaller pipe had $0.63 \times 0.63 \mathrm{~cm}$ steel hardware cloth affixed to one end using epoxy glue. Carrion was placed inside the smaller pipe before its insertion into the larger pipe. The screen end of the small pipe was oriented up to prevent $N$. americanus from contacting the bait. This trap does not require a rain shield because water drains through the pipe, which is open at both ends.

Cup traps were made from 1.0 liter plastic cups (Figs. 1a, c, d, f). The procedure for trap installation was similar for all cup traps. The double cup trap (Fig. 2c) was constructed by removing the base of one cup and placing it in a second cup. More of the cup's base was removed when larger amounts of bait were used. Bait was placed in the bottom of the whole cup, and the second cup (screen attached with duct tape over base) was placed inside the first cup. The nested cups were then buried so that their rims were flush with the soil surface. Variations of the cup trap and the bucket with lid trap are shown in Figures 1a, d, e, f.

The double bucket trap consisted of two, five-gallon (18.9 liter) buckets (Fig. 2) and was functionally similar to the double cup trap (Fig. 2c). The outer bucket was unaltered. The bottom $4 \mathrm{~cm}$ of the second bucket was removed and then covered with metal window screen affixed with duct tape. A large amount of carrion, such as a whole opossum, was placed at the bottom of the outer bucket. The second bucket was then placed inside the first. The two buckets (as one unit) were then buried in the ground with the rim of the upper bucket flush with the surface.

The single bucket trap (Fig. 3) was a five gallon (18.9 liter) white plastic bucket. Buckets were taken to the field and buried in the ground with the rim flush to the surface. Traps were baited with aged carrion placed in the bottom of the bucket. The bait was enclosed in a 0.47 liter, screen-topped, plastic container to prevent beetles from coming into contact with it.

Bait and Trapping Procedures. Lab rats (thawed from frozen specimens), fresh road kills, and other carrion were used as available, including mammals, birds, reptiles, amphibians, and fish. Frozen lab rats (commercially purchased) were thawed and aged in a resealable plastic bag for three days before being set out as bait in 1995. In 1996, lab rats were unavailable, and other sources of carrion were used. Roadside carrion was used in both years and comprised the bulk of bait used during the second year. In the course of our research, Bedick traveled the same roads every day and so could be assured of the age of carrion found within 8-12 hours. Traps were placed after 4 PM and left through the night. The traps were left in place for a minimum of three consecutive nights and checked each morning for beetles (trapping dates are reported as the date the traps were checked rather than the date the traps were placed). All beetles were removed, and silphids were identified (using keys from Ratcliffe 1996) and counted. Any N. americanus were sexed. Males are distinguished by the large, orange rectangle on the clypeus whereas females have a small, orange triangle on the clypeus. All $N$. americanus collected were marked at the apex of the elytra with Testors ${ }^{\circledR}$ enamel paint using different combinations of color and pattern, and details regarding beetle appearance were recorded. Records were kept of the colors and patterns of each beetle, and re-captures of individual beetles were also recorded.

Trap Effectiveness and Topography. To test the hypothesis that trap placement affects trap capture success, sets of single bucket traps were placed in Snell Canyon (a 


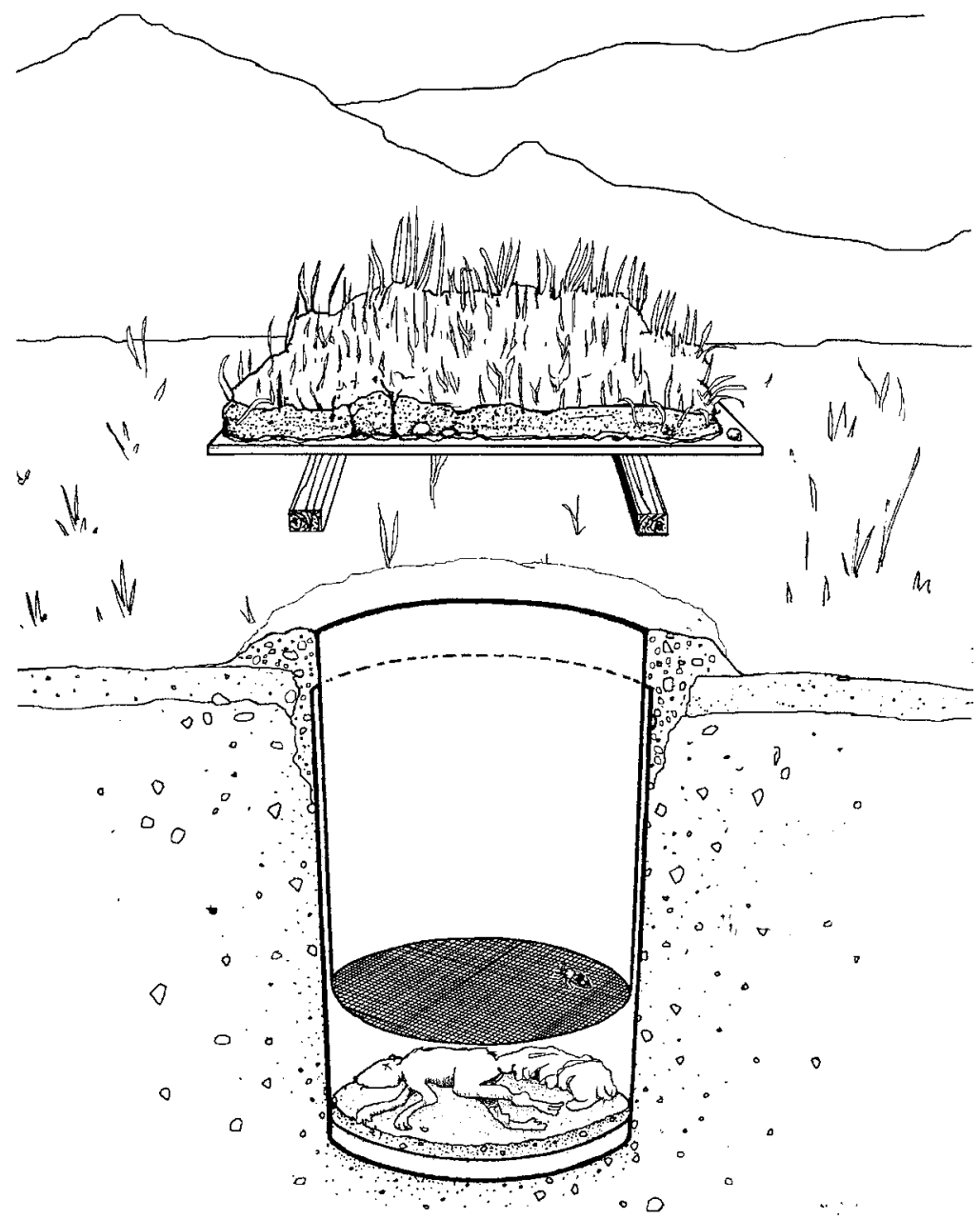

Fig. 2. Double bucket trap. The bottom of one bucket was removed and replaced by window screen; the screen bucket was placed within the second bucket containing whole carrion.

valley in Lincoln County) and along the ridge tops surrounding it. Eight pitfall buckets were used, and each pair was baited with the same carrion mixture. The pitfalls were paired: one trap in the valley and one trap on an adjoining ridge (Fig. 4). Four replicates were placed in a north-south direction. The pairs were alternated to the east side of the valley/west ridge and then the west side of the valley/east ridge. Each pair of traps was placed 200-400 m apart. Each set of traps was placed a minimum of $1 \mathrm{~km}$ apart. Trapping continued for six consecutive days (14-19 August 1996). The traps were checked each morning, and the beetles were quantified as previously described. 


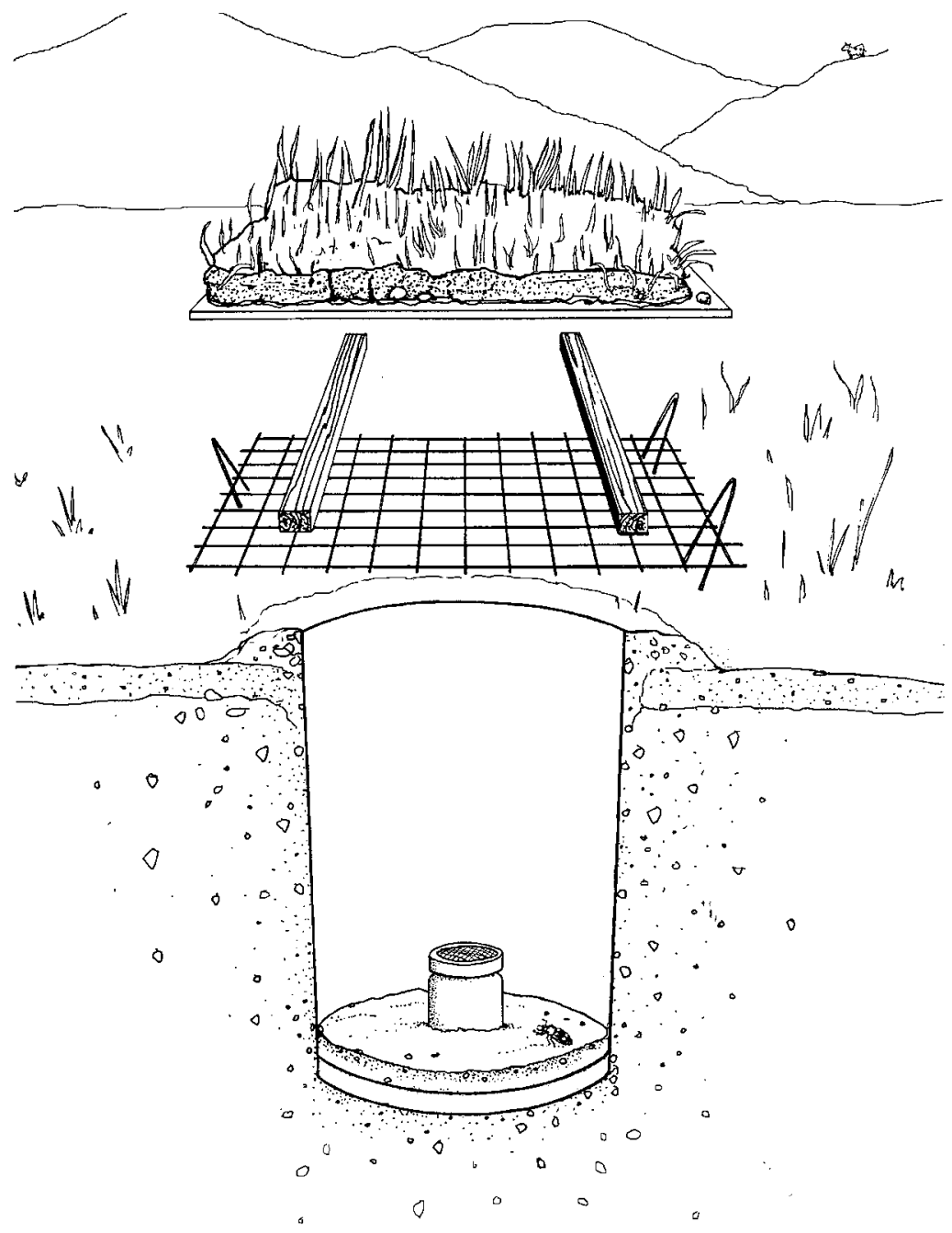

Fig. 3. The 18.9 liter bucket used for the majority of this study. The bucket was buried in the ground and a berm of soil $(6-8 \mathrm{~cm})$ was formed around the bucket lip. Bait is placed in the screen container. A plastic rain cover is placed over the bucket and supported by wood or stones. Wire screen is used over the bucket in areas with vertebrate scavenger activity.

\section{Results and Discussion}

Trapping Techniques. For most insect sampling, the key issue is sampling efficiency and numbers collected per unit of effort. However, in sampling an endangered species, minimizing mortality during sampling is a key requirement. In evaluating trapping methods for $N$. americanus, we needed to weigh both efficiency and survivorship with emphasis on survivorship.

With these requirements, trapping results indicated that a five-gallon bucket was the best, although perhaps not the most practical, pitfall trap. Small diameter cups and pipe 


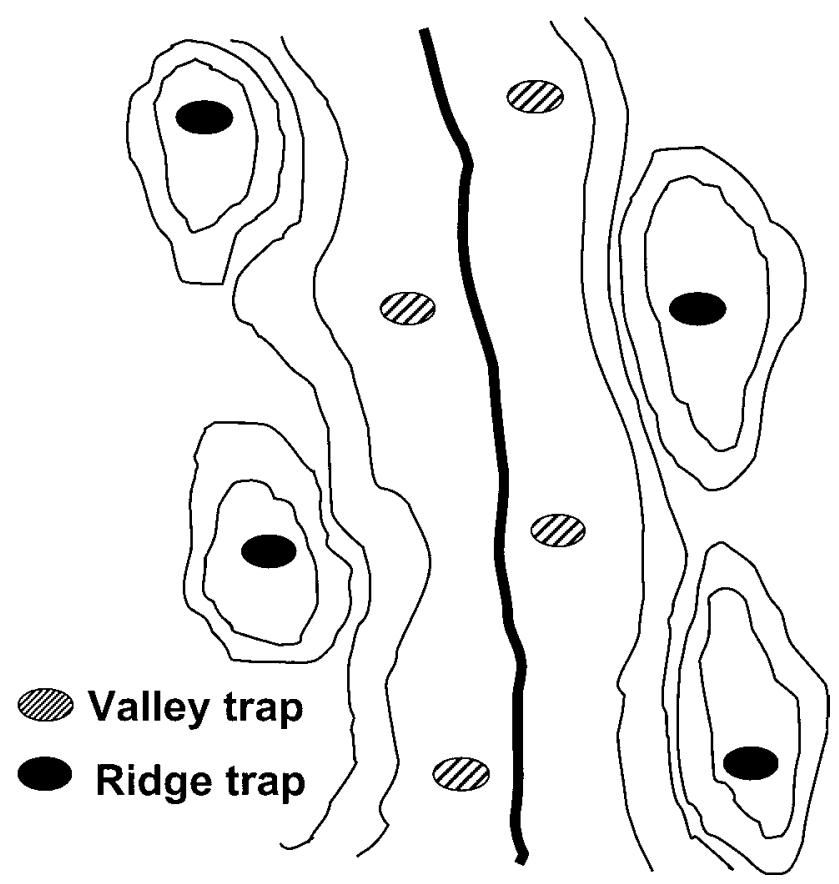

Fig. 4. Schematic showing placement of valley and ridge traps.

traps attracted beetles well, but severe crowding in some traps (up to 300 silphids/trap) resulted in beetles becoming agitated and secreting strong-smelling oral fluids that are strongly basic ( $\mathrm{pH}$ of 10.0, Rana et al. 1997), and anal fluids of waste products. Many beetles died under these conditions. Some species, such as $N$. tomentosus Weber, were able to breach the inner pipe and reach the carrion or the soil below, and this behavior made accurate counts of specimens difficult. It quickly became apparent that other traps should be tried.

Several traps constructed from plastic cups were tested (Figs. 1a, c, d, f). These designs prevented direct beetle contact with the carrion and beetle waste products, but because of the limited space and high beetle numbers, stacking remained a problem. Some of the modified traps (Figs. 1a, d) reduced waste accumulation by providing better drainage. The three-cup trap still promoted beetle stacking (Fig. 1a). The bucketwith-lid trap (Fig. 1c) remained cooler to touch but failed to attract many beetles. An advantage of using the double bucket design was the ability to use whole, large carrion while maintaining separation of the beetles from the carrion. However, the double bucket trap takes more time to construct, and beetles may be subjected to an increased threat of desiccation since there is no soil substrate.

Ultimately, the single, five-gallon bucket (Fig. 3) provided more surface area for each beetle, better ventilation, and beetles could use the soil in the bottom of the bucket to escape from other beetles. There are additional advantages with the larger size of the bucket, including easy access for clearing the trap, easier monitoring of bait, and the opportunity to observe beetles before releasing them. Obviously, however, placing such a large container in rocky soil is a problem, and each investigator will need to determine if this is practical for their situation. 
To reduce or avoid beetle mortality in traps, we made various modifications in the trap design. Rain was much more frequent during the second year of study, and so we modified bucket burial by building a small berm $(6-8 \mathrm{~cm})$ of soil to the bucket lip. This prevented locally pooling rainwater from entering the trap. A weighted, hard plastic rain-shield larger than the opening of the bucket was also placed over the bucket. Two cut branches or boards (3-4 cm thick) served as spacers between the bucket mouth and the rain shield.

If a trap site was believed to be in an area of high vertebrate scavenger activity, a wire screen mesh (screen size $2.54 \mathrm{~cm} \times 2.54 \mathrm{~cm}$ ) was added to the trap between the cut branches and the bucket mouth. The mesh was secured using three to four bent wire stakes, each $10 \mathrm{~cm}$ in length, driven into the ground. Soil was placed in the bottom of the bucket to a depth of $2-4 \mathrm{~cm}$.

The current USFWS trapping protocol states that bait should be held in a screened container so that the beetles do not come in direct contact with it to eliminate the possibility of blocking their spiracles. While carrion beetles are seemingly well-adapted to moving around in carrion, we found that under some conditions spiracle blocking could happen. For example, if the bait is placed in a small $(<6 \mathrm{~cm}$ diameter) trap with a water-tight bottom, the bait could decay into a near liquid state, which could adhere to beetles, harden, and then clog spiracles. However, when a larger trap ( 5 gallon bucket) is used, the risk is greatly reduced since carrion bait is more likely to desiccate than liquefy. Soil placed in the bottom of the bucket further reduced such risk since the soil absorbed some liquids. Because Nicrophorus species are well-adapted to moving over and in carrion, we believe that there is a greater problem with consuming and depleting the bait than with any potential mortality from contacting the bait.

Adding water to soil in the bottom of the pitfall trap helped maintain high humidity, which improves the longevity of burying beetles (Bedick and Wyatt Hoback unpubl. data). Water-loss experiments indicated that $30 \%$ water-loss was fatal to N. marginatus Fabr. Beetles died within 8-16 hours when placed in conditions of low humidity. Beetles placed in conditions of high humidity had near zero mortality even when the temperature was maintained at $28^{\circ} \mathrm{C}$. The sensitivity of $N$. marginatus to water-loss suggests that desiccation poses a greater problem to trapped beetles than would high temperatures alone. Maintaining damp soil in the traps will reduce water-loss induced mortality in beetles within the trap.

With the bucket traps, we collected 30,900 silphids in the traps during the two seasons of research. Of the silphids attracted, 21,108 were Nicrophorus species. Of these, $545(1.78 \%)$ were $N$. americanus. Not surprisingly, the trapping success rates were different between the two years. Trapping success is expressed as N. americanus per trap-night, which is the total number of $N$. americanus captured divided by the number of traps used which have been multiplied by the number of nights the traps were set out. In 1995, $75 \mathrm{~N}$. americanus were captured in 226 trap-nights for an average success rate of $0.3 \mathrm{~N}$. americanus/trap-night. In 1996, $470 \mathrm{~N}$. americanus were captured in 463 trap-nights for an average success rate of $1.0 \mathrm{~N}$. americanus/trap-night. The second season was longer, more traps were placed, and each trap was monitored for a longer duration.

Bait. The best approach for identifying possible discrimination of N. americanus to different carrion types would be through a controlled experiment with standardized carrion (the same mass and age). We tried different types of carrion as bait and looked for gross differences in attractiveness among carrion types. Table 1 summarizes our results. All major classes of animal carrion attracted $N$. americanus. Previously frozen lab rats (which were thawed and aged), as well as fresh carrion, were used during the two seasons. The fresh carrion was initially a better attractant than the rats. This occurred even when the rats were aged for three days. Despite the initial difference in 
Table 1. Carrion types used in this study and the number of American burying beetles (ABB) attracted.

\begin{tabular}{|c|c|c|c|c|c|}
\hline Carrion type & Trap-nights & $\mathrm{ABB}$ & $\begin{array}{l}\text { ABB per } \\
\text { trap-night* }\end{array}$ & Recaptures & $\begin{array}{l}\text { Total ABB } \\
\text { trap-night } \dagger\end{array}$ \\
\hline Badger & 7 & 4 & 0.571 & 0 & 0.571 \\
\hline Cat (domestic) & 19 & 13 & 0.684 & 3 & 0.842 \\
\hline Coyote & 7 & 0 & 0 & 0 & 0 \\
\hline Jackrabbit & 36 & 18 & 0.500 & 6 & 0.667 \\
\hline Opossum & 5 & 0 & 0 & 0 & 0 \\
\hline Pig (domestic) & 9 & 2 & 0.222 & 0 & 0.222 \\
\hline Rat (white lab rat) & 178 & 149 & 0.837 & 28 & 0.994 \\
\hline Squirrel (gray) & 27 & 56 & 2.074 & 34 & 3.333 \\
\hline Badger \& squirrel & 6 & 2 & 0.333 & 1 & 0.500 \\
\hline Cat \& rat & 3 & 3 & 1.000 & 0 & 1.000 \\
\hline Total: Mammals & 297 & 247 & 0.832 & 72 & 1.074 \\
\hline Snake (rattlesnake) & 6 & 10 & 1.667 & 5 & 2.500 \\
\hline Snake (bull snake) & 12 & 13 & 1.083 & 5 & 1.500 \\
\hline Toad (Bufo species) & 13 & 16 & 1.231 & 1 & 1.308 \\
\hline Turtle (ornate box turtle) & 25 & 33 & 1.320 & 12 & 1.800 \\
\hline Toad \& snake & 14 & 11 & 0.786 & 7 & 1.286 \\
\hline Total: Herptiles & 70 & 83 & 1.186 & 30 & 1.614 \\
\hline Dove (mourning dove) & 30 & 31 & 1.033 & 9 & 1.333 \\
\hline Turkey (giblets) & 3 & 1 & 0.333 & 0 & 0.333 \\
\hline Total: Birds & 33 & 32 & 0.970 & 9 & 1.242 \\
\hline Fish (scraps) & 6 & 6 & 1.000 & 3 & 1.500 \\
\hline Cat \& green racer & 2 & 1 & 0.500 & 0 & 0.500 \\
\hline Rat \& ornate box turtle & 4 & 2 & 0.500 & 0 & 0.500 \\
\hline Rat \& bull snake & 47 & 36 & 0.766 & 6 & 0.894 \\
\hline Rat \& rattlesnake & 36 & 39 & 1.083 & 15 & 1.500 \\
\hline Squirrel \& rattlesnake & 4 & 9 & 2.250 & 2 & 2.750 \\
\hline Squirrel, snake, box turtle & 2 & 3 & 1.500 & 0 & 1.500 \\
\hline Mixed carrion (other) & 55 & 80 & 1.455 & 26 & 1.927 \\
\hline Total: mixed carrion & 150 & 170 & 1.133 & 49 & 1.460 \\
\hline Total: all carrion types & 562 & 538 & 0.957 & 163 & 1.247 \\
\hline
\end{tabular}

* ABB per trap-night includes only first captures.

$\uparrow$ Total ABB per trap-night includes recaptures with first captures.

attractiveness, the overall capture rate for $N$. americanus using the lab rats was comparable to other types of carrion (Table 1).

Trap Effectiveness and Topography. Sampling from paired bucket traps on ridgetop and valley locations produced a total of $83 \mathrm{~N}$. americanus over a six day sampling period. The captures include recaptures, and the mean totals for six days are shown in Figure 5. Thirty $N$. americanus were captured in the valley and 53 on the ridges. Analysis of variance over time using SAS showed no significant difference for the effect of time $\left(\mathrm{F}_{1,5}=1.76, P=0.15\right)$. The traps placed on the ridges attracted significantly more beetles than the traps placed in the valley $\left(\mathrm{F}_{1,3}=4.37, P=0.0451\right)$.

Greater trap captures on ridge tops may have resulted from increased movement of odors associated with bait decay than occurred in valleys, thus improving the possibility of detection by beetles. In addition, beetle activity could be favored by warmer temperature on the ridge tops. During one session of nocturnal trapping, several 


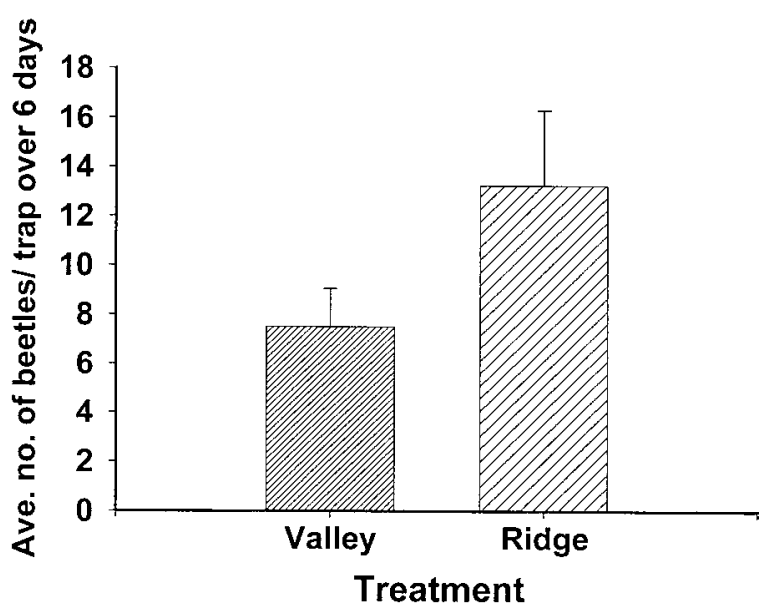

Fig. 5. Mean captures of American burying beetles in Snell Canyon valley and on surrounding ridges.

paired temperature readings (10 min apart) were taken on a ridge top and a valley. The temperature readings (4 pairs) were within $1^{\circ} \mathrm{C}$ of each other, with the ridge consistently having the warmer reading.

Ridges selected for this experiment rise 46-76 m above the valley. During the 1996 season several recaptures involved movement of beetles from one valley to another. The long distance movement and the results of the ridge-valley experiment demonstrate that the beetles are not limited to the valleys where most of the trees are found. Moreover, the results suggest that the beetles will fly over intervening ridges between the valleys. Creighton and Schnell (1998), working in Oklahoma and Arkansas, observed individual beetles moving between different habitat types, including movement between grasslands and woodlands as well as between bottomland and upland woodlands.

Trap Attractiveness. The number of traps and the relative distance between them may influence the capture of $N$. americanus. American burying beetles can be attracted to carrion from distances ranging from $0.25-10.0 \mathrm{~km}$ over a six night period with an average of $1.23 \mathrm{~km} / \mathrm{night}$ (Creighton and Schnell 1998), and Peyton (1996) recovered a specimen from as far away as $11.2 \mathrm{~km}$. In this study there were five recaptures from distances of 3-6 km. Placing traps in proximity may decrease individual trap success rates as multiple traps compete for the same localized population.

It is possible that trapping success rate is more a function of carrion mass and not the number of traps. The large proportion $(85 \%)$ of recaptures in our study came from a distance $0.5 \mathrm{~km}$ or less (Bedick et al. 1999). Consequently, for traps with large amounts of bait, we suggest that $0.5 \mathrm{~km}$ be used as a minimum for trap spacing.

Trap Timing. Trapping for $N$. americanus should be done when beetle activity is highest to maximize trapping success. The standard has been to set traps 3-8 weeks after the onset of seasonal activity in late spring and early summer. Typically, traps are set each night and checked each morning for results. Pitfall captures have been reported as greatest from mid-June through early July with activity decreasing sharply thereafter (U.S. Fish and Wildlife Service 1991).

These results do not agree with our observations of the Gothenburg population (Fig. 6). We had high capture success for $N$. americanus from late June through early 


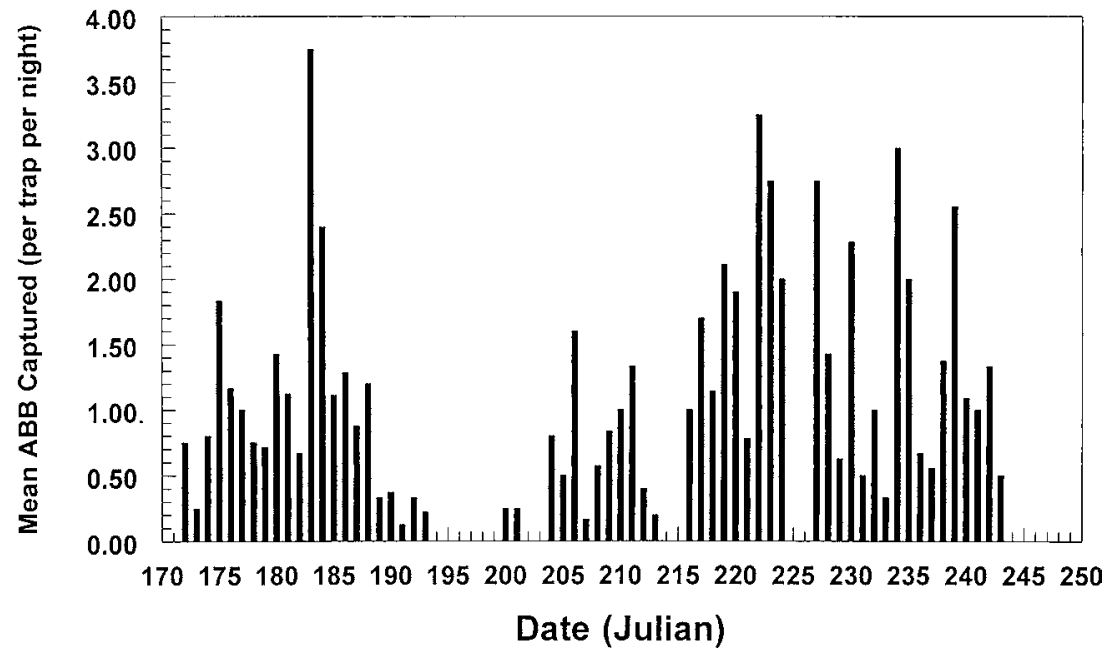

Fig. 6. Mean number of $N$. americanus captured per trap night during 1996.

July 1996, and then captures began to drop off through the remainder of July. However, captures increased in August and there was a second, larger peak in mid-August. Other research in Nebraska resulted in the capture of $N$. americanus from 20 May through June (Peyton 1996), but our results indicate that field studies and surveys for the beetle can be done over a greater period of the season. The most productive part of the trapping season is mid-June through mid-July (the overwintering generation) and during the month of August (the new generation).

Factors Affecting Beetle Mortality in Traps. Many factors can increase trap mortality for $N$. americanus. During the two seasons of study, we observed several proven or potential factors resulting in mortality. Throughout the 1996 season, rainfall was above average in the study area. It was not unusual to have $1-5 \mathrm{~cm}$ of precipitation in as little as one hour during July and August, which often resulted in flooding at trap sites. Due to these weather conditions, and in spite of precautions taken (rain cover and soil berm), several traps were flooded. On four occasions $N$. americanus were found floating in the traps. The first time this occurred (late July), a single beetle was found dead. In three other instances, floating and apparently dead beetles (seven specimens) were removed from traps, and they subsequently recovered after 10-20 min.

Conclusions. Although the single, large bucket trap was best for trapping the American burying beetle, it may not be practical to use in all soil types. Nicrophorus americanus was attracted to all major classes of animal bait that were tested. Moreover, $N$. americanus was attracted to a wide range of bait ages and stages of decay. Sampling, at least for the Nebraska population, can begin earlier in the season than has previously been suggested, and the greatest captures are expected during late June to early July and mid-August. The daily activity of $N$. americanus was greatest during the third and fourth hours after sunset.

\section{New Sampling Protocol Recommendations}

Our results indicated that new procedures are appropriate when sampling for the American burying beetle, and we propose that the USFWS protocol be revised accordingly. The single bucket trap is the basic trapping unit. Ideally, a 5-gallon (18.9 
Table 2. Revised sampling protocol for N. americanus based on USFWS (1991) recovery plan and results reported here.

Trap

1. Bucket trap: ideally, 5-gallon (18.9 liter) plastic bucket (smaller, if substrate is rocky)

2. Bucket buried in ground leaving $6-8 \mathrm{~cm}$ of bucket exposed

3. Berm of soil $6-8 \mathrm{~cm}$ built up to lip of bucket

4. Plastic or wooden rain shield exceeding size of bucket mouth by $5-8 \mathrm{~cm}$

5. Soil mounded on top of the rain shield to weight and insulate it

6. In areas of suspected scavenger activity, wire mesh (such as hardware cloth; mesh dimension $2 \times 2 \mathrm{~cm}$ ) should be placed over mouth of bucket and secured with stakes

7. Provide $2-4 \mathrm{~cm}$ damp soil substrate in bottom of trap

8. Light trapping optional

\section{Bait}

1. Aged 3 days if previously frozen

2. Aged 1 day if bait is fresh

3. Minimum of $200 \mathrm{~g}$ of carrion per trap

4. Place bait in one liter, screened or plastic container

\section{Placement and timing}

1. Individual traps placed a minimum of $0.5 \mathrm{~km}$ apart

2. Choose a variety of sites; avoid agricultural areas that may be treated with pesticides

3. Do not locate traps near ant nests; if ants enter trap, relocate trap

4. Do not place in dense woods

5. Trapping conducted throughout summer months beginning in mid-June and ending in late August (Nebraska data)

6. Pitfall captures generally higher when night time lows are above $15^{\circ} \mathrm{C}$

7. If early evening temperatures remain warm, chances for captures should remain high

\section{Trapping interval and collection}

1. Service trap each morning, preferably before temperatures become hot

2. For establishing presence of beetles, maintain traps for minimum of 3 days; 5 days is better

3. Remove all insects captured each day

4. Replace bait as needed

5. Close or remove trap when not in use

\section{Intensive sampling}

1. Mark beetles using enamel model paint at base of elytra; alternatively the elytra can be notched at apex

2. Transport beetles in a chilled container

3. Release all beetles up-wind of traps

liter; or smaller, depending on substrate) plastic bucket is buried in the ground and a berm of soil built up to the lip to a height of $6-8 \mathrm{~cm}$. A large mesh $(2.5 \times 2.5 \mathrm{~cm})$ wire screen cover (staked down) should be used in areas where vertebrate scavengers will disturb traps. A rain shield (plastic, wood, preferably not metal due to possible heat reflection) with dimensions exceeding the bucket mouth by $5-8 \mathrm{~cm}$ is placed on top with space between the trap and cover for beetle entry; soil mounded on top of the rain shield helps to insulate the bucket and prevent the cover from blowing off. Bait should be aged for three days if previously frozen or, if fresh, one day. For general surveying purposes, we suggest using a minimum of $200 \mathrm{~g}$ of carrion although more carrion may be desirable. Placing carrion in a one liter, screened container is necessary where beetles may consume the bait. Barring the beetles from the bait will extend the length of time the bait can be used. Excluding beetles from bait is not needed for short duration trapping 
sessions where the goal is to establish only the presence of $N$. americanus. Under all circumstances, $2-4 \mathrm{~cm}$ of damp soil should be maintained in the bottom of the trap. Trap surveying could be conducted in the early evening hours, and then the traps could be removed or closed at midnight. The USFWS recommendation that traps be cleared of beetles by 9 AM every day is probably not necessary if moisture is maintained in the traps. It is heat in the absence of moisture that is lethal to the beetles. There are also logistical problems with trying to clear 30-50 traps by 9 AM, especially if they are some distance apart. Individual traps should be placed a minimum of $0.5 \mathrm{~km}$ apart. Table 2 presents a sampling protocol for $N$. americanus, which follows from the original USFWS recovery plan and reflects modifications based on results reported here.

\section{Acknowledgments}

We thank W. Wyatt Hoback for his encouragement and collaboration with Bedick on the water-loss experiments. David Stanley (University of Nebraska) is acknowledged for the use of his laboratory for the water-loss experiments. We thank Mark Peyton (Central Nebraska Public Power and Irrigation District) for his assistance to Bedick in the study area; Mary Liz Jameson (University of Nebraska) for sharing her advice and experiences with Nicrophorus americanus; and Dick Nelson (Nebraska Game and Parks Commission) for logistical support to Bedick in the form of an all terrain vehicle with which to survey part of the study area. We are deeply grateful to the Nebraska Game and Parks Commission (Mike Fritz) for providing funds to conduct these studies and the U.S. Fish and Wildlife Service (Wally Jobman) for assistance with the permitting process for working with endangered species. Lastly, we thank the people who work and live in the Loess Hills study area without whose help and cooperation this study would not have been successful.

\section{Literature Cited}

Backlund, D. C., and D. C. Marrone. 1997. New records of the endangered American burying beetle, Nicrophorus americanus Olivier (Coleoptera: Silphidae), in South Dakota. Coleopterists Bulletin 51:53-58.

Bedick, J. C., B. C. Ratcliffe, W. W. Hoback, and L. G. Higley. 1999. Distribution, ecology, and population dynamics of the American burying beetle [Nicrophorus americanus Olivier (Coleoptera, Silphidae)] in south-central Nebraska, USA. Journal of Insect Conservation 3:171-181.

Creighton, J. C., and G. D. Schnell. 1998. Short-term movement patterns of the endangered American burying beetle Nicrophorus americanus. Biological Conservation 86:281287.

Creighton, J. C., C. V. Vaughn, and B. R. Chapman. 1993. Habitat preference of the endangered American burying beetle (Nicrophorus americanus) in Oklahoma. The Southwestern Naturalist 38:275-306.

Eggert, A.-K., and J. K. Müller. 1989. Pheromone-mediated attraction in burying beetles. Ecological Entomology 14:235-237.

Kozol, A. J. 1989. Studies on the American burying beetle, Nicrophorus americanus, on Block Island. Unpublished report to the Nature Conservancy, Boston, MA. $10 \mathrm{pp.}$

Kozol, A. 1991. Appendix 2. Survey protocol for Nicrophorus americanus, the American burying beetle [pp. 1-6]. In: U.S. Fish and Wildlife Service, American Burying Beetle (Nicrophorus americanus) Recovery Plan. Newton Corner, MA. 80 pp.

Kozol, A. J., M. P. Scott, and J. F. A. Traniello. 1988. The American burying beetle, Nicrophorus americanus: studies on the natural history of a declining species. Psyche 95:167-176.

Lomolino, M. V., J. C. Creighton, G. D. Schnell, and D. L. Certain. 1995. Ecology and conservation of the endangered American burying beetle (Nicrophorus americanus). Conservation Biology 9:605-614. 
Lomolino, M. V., and J. C. Creighton. 1996. Habitat selection, breeding success and conservation of the endangered American burying beetle, Nicrophorus americanus. Biological Conservation 77:235-241.

Miller, E. J., and L. Mcdonald. 1997. Rediscovery of Nicrophorus americanus Olivier (Coleoptera: Silphidae) in Kansas. Coleopterists Bulletin 51:22.

Muths, E., and M. P. Scott. 2000. American burying beetle [pp. 10-15, 322-323]. In: Endangered animals (R. P. Reading and B. Miller editors). A Reference Guide to Conflicting Issues. Greenwood Press, Westport, CT.

Peyton, M. M. 1996. The American burying beetle (Nicrophorus americanus). Range and population study for the dissected hills south of the Platte River, Dawson and Lincoln Counties, Nebraska, 1966. Unpublished report to the U.S. Fish and Wildlife Service and the Nebraska Game and Parks Commission. 16 pp.

Rana, R. L., W. W. Hoback, A. R. Nor Aliza, J. Bedick, and D. W. Stanley. 1997. Pre-oral digestion: a phospholipase $\mathrm{A}_{2}$ associated with oral secretions in adult burying beetles, Nicrophorus marginatus. Comparative Biochemistry and Physiology 118B:375-380.

Ratcliffe, B. C. 1996. The carrion beetles (Coleoptera: Silphidae) of Nebraska. Bulletin of the University of Nebraska State Museum 13:1-100.

Ratcliffe, B. C., and M. L. Jameson. 1992. New Nebraska occurrences of the endangered American burying beetle (Coleoptera: Silphidae). Coleopterists Bulletin 46:421-425.

Recce, S. 1988. Endangered and threatened wildlife and plants: proposed endangered status for the American burying beetle. Federal Register 53(196):39, 617-621.

Southwood, T. R. E. 1978. Ecological methods. 2nd ed. Wiley and Sons, New York, NY.

U.S. Fish and Wildlife Service. 1991. American burying beetle (Nicrophorus americanus) recovery plan. Newton Corner, MA. 80 pp.

(Received 5 June 2002; accepted 14 February 2003. Publication date 2 April 2004.) 